\title{
Lilac Cultivar Name Registration 1998
}

\author{
Freek Vrugtman ${ }^{1}$ \\ Royal Botanical Gardens, Box 399, Hamilton, Ontario L8N 3H8, Canada
}

All correspondence concerned with additional information or plants or propagules of newly registered lilac cultivars should be directed to the registrants listed below, not to the Registrar.

Commencing with 1995 lilac registrations, standard portfolios are being established in accordance with Principle 3 and Articles 12, 22 (Recommendations $22 \mathrm{G} \& 22 \mathrm{H}$ ), and 32 of the International Code of Nomenclature for Cultivated Plants-1995 (ICNCP-1995). Previous registration lists of Syring a cultivar names appeared in AABGA Bulle$\operatorname{tin}[13(4): 105-110 ; 14(3): 95 ; 15(3): 71-72 ; 16(4): 131-132 ; 17(3): 67-$

${ }^{1}$ Registrar, International Registration Authority for cultivar names in the genus Syringa L. Contribution No. 97, Royal Botanical Gardens, Hamilton, Ontario, Canada.
69; 18(3):87]; HortScience [23(3):458; 24(3):435-436; 25(6):618; 26(5):476-477;29(9):972;31(3):327-328;32(4):587-588;33(4):588589].

Syringa $\times$ chinensis Willdenow 'Lilac Sunday' was registered 7 Feb. 1998 by John H. Alexander III, Plant Propagator, The Arnold Arboretum, 125 Arborway, Jamaica Plain, MA 02130, USA. The ortet (original plant), accessioned as AA 224-79*E and AA 127-96, was selected by Alexander from seedlings grown from seed of unknown parentage, and named in 1996. History and description of 'Lilac Sunday' have been published in Arnoldia 57(1):12-13 and back cover illustration [1997]. Plants are propagated easily from cuttings and have been distributed by The Arnold Arboretum since Sept. 1997. A standard portfolio has been opened at Royal Botanical Gardens Herbarium, Hamilton, Ontario, Canada, but is still incomplete. 